\title{
Assessment of Serum Lactoferrin Level in Patients with Acne Vulgaris
}

O.H.ALKady, A.Adel ALF Allah, H.E.Abd Al-Aal and A.G.Elwan

Dermatology, Venereology and Andrology Dept., Faculty of Medicine, Benha Univ., Benha, Egypt E-Mail: Arwa2000@gmail.com

\begin{abstract}
Acne vulgaris is a chronic inflammatory disease of the pilosebaceous units (PSU) . In 2015, acne was estimated to affect 633 million people globally, making it the eighth most normal infection worldwide.Few contemplates revealed that huge numbers of skin break out patients had worthy helpful reaction with a decrease of skin break out sores with joined utilization of effective retinol and oral lactoferrin in mellow and moderate skin inflammation. We planned to assess the serum level of lactoferrin in patients with skin break out vulgaris and connect its level with a seriousness of skin break out. Strategies: An imminent case-control interventional study included 90 members devided to Group A: 70 patients clinically analyzed as skin break out vulgaris. Gathering B : included 20 clearly solid (control gathering). Serum lactoferrin had been estimated in the two patients and control subjects . Results: there was an exceptionally factually huge negative connection between's illness length and serum lactoferrin level among case gathering. there was a critical connection among lactoferrin and Acne seriousness, this connection can be utilized to anticipate the seriousness of the infection, at cut off estimation of lactoferrin $>174.2$ with great prescient separate among gentle and extreme Acne, AUC $=0.979$ Conclusion:. This clinical examination exhibited that serum LF level is straightforwardly identified with serious skin break out in the intense stages as opposed to mellow interminable skin break out. Accordingly, it could be of prognostic incentive as a marker of seriousness and could be then utilized for remedial arranging and development.
\end{abstract}

\section{Introduction}

Acne vulgaris is a chronic inflammatory sickness of the pilosebaceous units (PSU) and is described by seborrhea, the development of comedones, erythematous papules and pustules, less often by knobs, profound pustules, or pseudocysts and sometimes, is joined by scarring [1].

Lactoferrin is an iron restricting glycoprotein which is known to have a job in diminishing aggravation and microbial disease. As an iron-restricting protein, it sequesters iron that is fundamental for microbial development, and it displays non-iron-subordinate bactericidal action by restricting straightforwardly to the bacterial layer and increment bacterial film porousness [1].

Lactoferrin is viewed as a first-line guard protein engaged with assurance against a huge number of microbial contaminations and controlling the arrival of proinflammatory cytokines. Along these lines, Lactoferrin diminishes skin aggravation because of its wide antibacterial and mitigating exercises [2].

Lactoferrin assumes significant job in balancing the provocative cycle by decreasing creation of some favorable to fiery cytokines, for example, tumor rot factor $(\mathrm{TNF} \alpha)$ or interleukins IL-1 and IL-6. Furthermore, expanded of mitigating interleukin IL-10 has additionally been accounted for in a few cases [3].

The Lactoferrin antibacterial action is checked by bacterial microorganisms through three fundamental components Iron securing through combination of high affinity ferric particle chelators named siderophores that rival iron-restricting proteins. Iron securing through official to LF, hemoglobin, haptoglobin, hemopexin and heme. Iron obtaining through bacterial reductase ready to diminish ferric to ferrous particles that inactively enter inside microbial cells [3].

Scarcely any investigations detailed that a significant number of skin break out patients had adequate remedial reaction with a decrease of skin break out sores with consolidated utilization of effective retinol and oral lactoferrin in gentle and moderate skin break out. Oral lactoferrin in gentle to direct skin inflammation vulgaris is very much endured and lead to a general improvement in skin inflammation when managed as dietary enhancement on a twice every day routine [4].

Oral organization of Lactoferrin-improved aged milk enhances skin break out vulgaris with a specific reduction of triacylglycerols in skin surface lipids [4].

The point of work was to assess the serum level of lactoferrin in patients with skin inflammation vulgaris and correlate its level with a severity of acne.

\section{Patient and method}

This was a forthcoming case-control interventional study that was led on patients with skin break out going to the Dermatology out-quiet center of Benha University Hospital in the period from septemper 2018 to walk 2019.

This investigation included 90 members of various sexual orientation and age gatherings. Members in this examination were partitioned into two gatherings:

\section{Gathering A (tolerant gathering)}

This gathering included 70 patients clinically analyzed as skin break out vulgaris.

Incorporation Criteria

Patients with various degrees of seriousness of AV as indicated by Global Acne Grading framework (GAGS) (Doshi et al., 1997).

Age went from 15 to 45 years.

The two sexes were incorporated.

Avoidance Criteria

\section{Gathering B (Control gathering)}

This gathering included 20 clearly solid, age and sex coordinated members as a benchmark group.

Patients were partitioned by GAGS into three gatherings, Mild (20 patients), moderate (20 patients) and extreme (20 patients). 
The absolute seriousness score was gotten from the summation of six provincial subscores. Each was inferred by increasing the factor for every district; (factor for brow and each cheek was 2, jawline and nose was 1 for each and chest and upper back was 3 for each); by the most intensely weighted injury inside every locale (1 for comedones, 2 for papules, 3 for pustules and 4 for knobs). A score of (1-18) is viewed as gentle; (19-30) moderate; (31-38) serious; and $>39$ exceptionally extreme (5).

Serum lactoferrin had been estimated in the two patients and control subjects utilizing packs bought from
Sun Red Bio (Shanghai-China) with Lot number 201-121720 and measure go from $12 \mathrm{ng} / \mathrm{ml}$ to $3000 \mathrm{ng} / \mathrm{ml}$.

\section{Results}

There is no significant difference between participants regarding age and sex. The age and sex distribution among the participants were demonstrated in

Lactoferrin was measured in serum of participants. In control group the lactoferrin level was $93.75 \pm 26.99$ and in cases group was 233.25 \pm 160.93 ). Serum Lactoferrin level was found to be significantly higher among studied patients than control group $(\mathrm{P}<0.001)$.

Table (1) Serum lactofrrin among the studied groups.

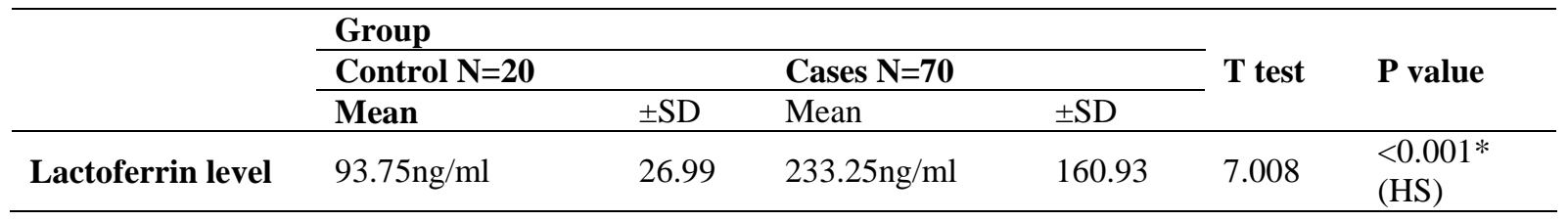

$$
\mathrm{T}=7.008 \rightarrow \mathrm{p} \text { value }<0.001(\mathrm{HS})
$$

There was a highly significant negative correlation between disease duration and serum lactoferrin level among patients group Fig (1).

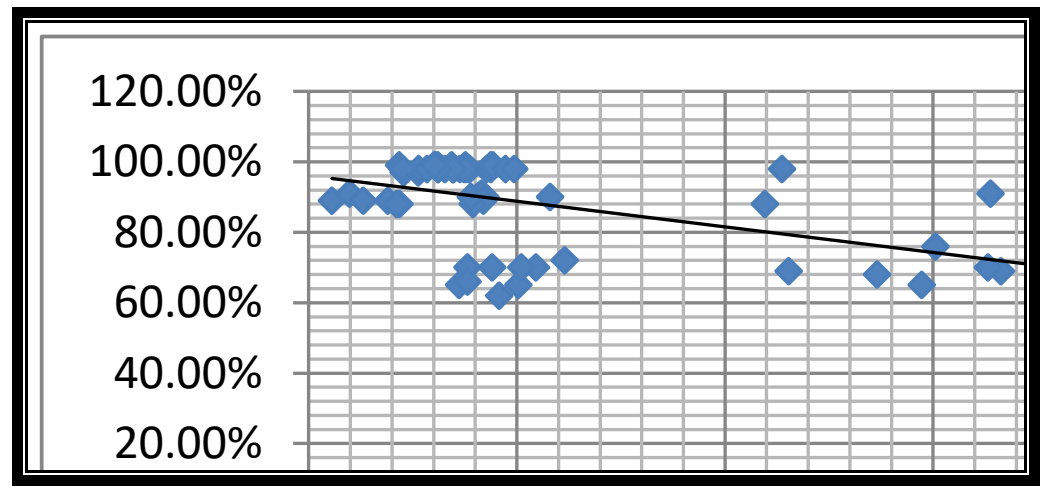

Fig (1) Correlations between Disease duration and lactoferrin among studied patients.

As there was a significant relation between lactoferrin and acne severity, this relation can be used to predict the severity of the disease, at cut off value of lactoferrin $>174.2$ with good predictive discriminate between mild and severe Acne, $\mathrm{AUC}=0.979$ Fig (2).

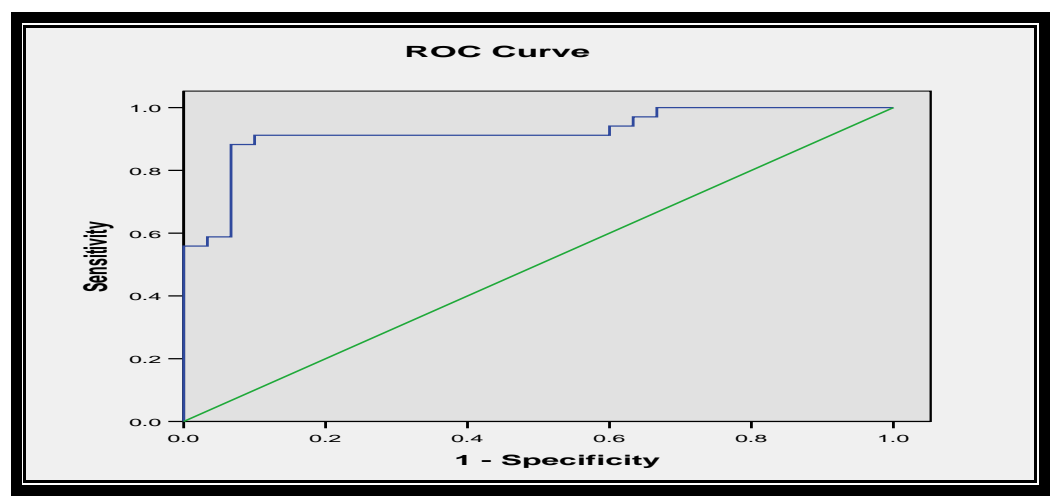

Fig (2) Roc curve using lactoferrin to discriminate Severe from mild acne cases.

\section{Discussion}

This investigation was a case control study, in which arbitrarily chose patients experiencing skin break out 
vulgaris of coordinated age and sex.They were isolated into 2 gatherings: quiet gathering: including 70 patients experiencing skin break out vulgaris (mellow moderateextreme). Control gathering: including 20 cases. The term of the investigation ran from 6 a year.

In this investigation, examination for age in cases bunch the scope old enough was 17-25 years (mean $21.27 \pm 2.23$ ). The 20 control subjects associated with our

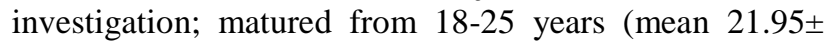
$2.44)$. In cases bunch 47 patients $(67.1 \%)$ were guys and $23(32.9 \%)$ were females. In control bunch 12 subjects were guys $(60 \%)$ and $8(40 \%)$ were females. They were age and sex coordinated with cases with no noteworthy separation. These outcomes were coordinated with investigation of $\mathrm{Kim}$ et al.[4], as they announced that there were no contrasts among male and female subjects for any of the pattern attributes; subsequently, the information for male and female subjects were consolidated. There was no distinction in age and sex between gatherings.

The soonest non-provocative sores in skin break out vulgaris are small scale comedones. As the injuries increment in size, they become non-excited shut or open comedones (whiteheads or zits, separately). In time the comedones may load up with Propionibacterium acnes microbes, which emit chemotactic, and proinflammatory side-effects, provocative cells encompass the follicule, scatter through the follicular divider, and lead to bigger and incendiary injuries, for example, papules, pustules, and nodulocystic sores [7].

The current examination demonstrated that as per the appropriation of the malady seriousness among the 70 cases, there were 35 cases with mellow infection seriousness (half) and 35 with extreme illness (half). These were in accordance with investigation of [8], as they announced that there were 20 cases with mellow sickness seriousness (half) and 20 with extreme illness (half). Notwithstanding, [3], found that $84 \%$ of their examined bunch had mellow malady seriousness and $16 \%$ of them had moderate illness seriousness.

The current investigation indicated that Lactoferrin was estimated in serum of members. In control bunch the lactoferrin level was $93.75 \pm 26.99$ and in cases bunch was 233.25 \pm 160.93 . Serum Lactoferrin level in patients with Acne Vulgaris was factually profoundly noteworthy than that in solid control subjects .This concurred with [8], as they revealed that Serum LF level in all patients with AV was fundamentally higher than that in sound controls [9], surveyed the cutaneous articulation of 20 antimicrobial peptides including LF, and results uncovered fundamentally expanded articulation in untreated aroused skin break out sores.

In this investigation there was no noteworthy contrast in serum lactoferrin level among guys and females among cases gathering. There was no critical relationship among's age and lactoferrin level among cases gathering. There was a profoundly critical contrast among gentle and extreme cases as respect serum lactoferrin level with more elevated level in serious cases. This concurred with (8), as they announced that serum LF levels were altogether lower in gentle skin break out cases $(142.75 \pm 28.90 \mathrm{ng} / \mathrm{ml})$ versus serious cases $(323.75 \pm 187.30 \mathrm{ng} / \mathrm{ml})$ and they were essentially higher in every subgroup contrasted and sound controls $(93.75 \pm 26.99 \mathrm{ng} / \mathrm{ml})$. Be that as it may, serum LF levels didn't vary among females versus guys in gentle skin break out cases $(\mathrm{P}=0.655)$, in extreme skin break out cases $(\mathrm{P}=0.915)$, or in controls $(\mathrm{P}=0.215)$. Also, serum LF level didn't associate with age too in mellow skin break out cases $(\mathrm{r}=0.158, \mathrm{P}=0.506)$, extreme skin break out cases $(\mathrm{r}=0.076, \mathrm{P}=0.750)$, or in controls $(\mathrm{r}=0.199, \mathrm{P}=0.4)$

This elevated level of LF in skin break out could be clarified by the way that LF biosynthesized by the forerunners of neutrophils is put away in the auxiliary granules of the develop cells. During disease and irritation and after incitement of neutrophils, $60-70 \%$ of the optional granules are released from the phones, and a lot of LF is freed in the blood. Attributable to the expansion in its focus during most fiery responses, a few analysts arrange LF as an intense stage reactant [10].

Lactoferrin is viewed as a first-line safeguard protein associated with insurance against a large number of microbial diseases and controlling the arrival of proinflammatory cytokines. In this way, Lactoferrin diminishes skin irritation because of its wide antibacterial and mitigating exercises [10]. LF can decrease the hurtful impact of responsive oxygen species created by leukocytes at the locales of aggravation [11].

In this examination, there was an exceptionally measurably huge negative connection between's infection length and serum lactoferrin level among case gathering. This concurred with [8], as they revealed that there was a factually critical negative relationship between's sickness span and serum LF between both case subgroups $(\mathrm{r}=-0.762)$. In addition, there was a critical negative connection between's sickness length and serum LF among gentle cases extreme cases, [12], found that serum LF level is contrarily corresponded with the term of skin break out, as it goes through freedom and digestion by the liver after subsidence of the intense stages.

As there was a critical connection among lactoferrin and Acne seriousness, this connection can be utilized to foresee the seriousness of the illness, at cut off estimation of lactoferrin >174.2 with great prescient segregate among gentle and extreme Acne, AUC=0.979. Utilizing serum lactoferrin level it was indicated that above 174.2, it can segregate between gentle case and serious cases with level of sensitivity94.1, particularity 93.3\%, PPV 94.6\% AND NPV 91.2\%. This concurred with [8], who announced that Using ROC bend, serum LF level above $175 \mathrm{ng} / \mathrm{ml}$ could segregate among mellow and serious skin break out cases, with affectability and explicitness of 95\%.Thus, serum LF level could be of prognostic incentive as a marker of seriousness and could be then utilized for restorative arranging and development, a case for additional bigger investigations.

Another examination by [4], who directed a randomized, twofold visually impaired, fake treatment controlled 12-week concentrate on the impacts of lactoferrin-improved aged milk in youthful grown-ups 
with mellow to direct skin break out vulgaris. In that review, skin break out improved in the lactoferrin bunch as reflected by a factually critical diminishing in all out injury check by $23.1 \%$ contrasted and the fake treatment gathering. Furthermore, fiery sore check was decreased by $38.6 \%$ at study end (p 1/4 0.019) contrasted and fake treatment. The perceptions were related with diminished sebum content in the lactoferrin gathering. They likewise revealed that admission of LF-improved aged milk brought about noteworthy decrease in provocative sore, and skin inflammation grade, as contrasted and the fake treatment gathering. Also, the sebum content in the LF bunch diminished fundamentally contrasted and the fake treatment group.

\section{References}

[1] F.Shams, S.Niaz, S.Zeeshan. Cardiff acne disability index based quality of life in acne patients, risk factors and associations. J.,Liaquat University. Medical Health Science, Vol.17 (01), PP.29-3,2018.

[2] L.Rosa, A.Cutone, M.Lepanto. Lactoferrin: a natural glycoprotein involved in iron and inflammatory homeostasis. International journal of molecular sciences, Vol.18(9), PP.19-85, 2017.

[3] H.Chan, G.Chan, J.Santo. A randomized, doubleblind, placebo-controlled trial to determine the efficacy and safety of lactoferrin with vitamin $\mathrm{E}$ and zinc as an oral therapy for mild to moderate acne vulgaris. International journal of dermatology, Vol.56(6), PP.686-690,2017.

[4] J.Kim, Y.Ko, Y.K.Park. ,2010.
[5] Dietary effect of lactoferrin-enriched fermented milk on skin surface lipid and clinical improvement of acne vulgaris. Nutrition, Vol.26, PP.902-909.

[6] A.Doshi A.Zaheer, J. Matthew. A comparison of current acne grading systems and proposal of a novel system. Internationat Journal Of Dermatology, Vol.36, PP.416-418. ,1997.

[7] A.Jahns, B.Lundskog, R.Gancevicien. An increased incidence of Propionibacterium acnes biofilms in acne vulgaris: a case-control study. $\mathrm{Br}$ J.,Dermatological science.Vol.167, PP.50-58, 2015.

[8] M.Sharara, H.Diab , M.Abd El Rahman. A pilot study on serum lactoferrin in patients with mild versus severe acne in correlation with disease duration. Journal of the Egyptian Women's Dermatologic Society, Vol.16 (3), PP.19-3 ,2019.

[9] A.Borovaya, Y.Dombrowski, S.Zwicker. Isotretinoin therapy changes the expression of antimicrobial peptides. Archives of Dermatological Research, Vol.306, PP.689-700,2014.

[10] T.Siqueiros-Cendón, S.Arévalo-Gallegos, B.F.Iglesias-Figueroa. Immunomodulatory effects of lactoferrin. Acta Pharmacol Sin, Vol.14, PP.557$566,2014$.

[11]P.P.Ward, E.Paz , O.M.Conneely. Multifunctional roles of lactoferrin: a critical overview. Cellular and Molecular Life Sciences, Vol.62, PP.25402548,2005.

[12] T.Kanyshkova, V.N.Buneva ， G.A.Nevinsky. Lactoferrin and its biological functions. Biochemistry, Vol.66, pp.1-7,2001. 